\title{
Prevention of Resulfurization in Desulfurization Process with Magnesium Vapor Produced in Situ by Aluminothermic Reduction of Magnesium Oxide
}

\author{
Jian YANG, Mamoru KUWABARA, Keiji OKUMURA ${ }^{11}$ and Masamichi SANO \\ Department of Materials, Physics and Energy Engineering, Graduate School of Engineering, Nagoya University, Furo-cho, \\ Chikusa-ku, Nagoya, Aichi-Ken 464-8603, Japan. \\ 1) Formerly Research Associate, Nagoya University; now is Associate \\ Professor, Department of Materials Science and Engineering, Faculty of Engineering, Nagoya Institute of Technology, Nagoya, \\ Aichi-ken 466-8555, Japan.
}

(Received on May 2, 2005; accepted on August 12, 2005)

\begin{abstract}
The mechanism of resulfurization in the desulfurization process with magnesium vapor produced in situ by aluminothermic reduction of magnesium oxide was clarified in the present work. The influences of various operating parameters on the resulfurization were studied and the methods that could prevent resulfurization were proposed.

There are two kinds of mechanisms of resulfurization in the desulfurization process with magnesium. One is decomposition of the desulfurization product of MgS under the inert atmosphere. The other is oxidation of MgS under the oxidative atmosphere.

Under the present experimental conditions, lowering operating temperature and oxygen partial pressure in the atmosphere, and adding more pellets containing magnesium oxide and aluminum could effectively prevent the resulfurization. The resufurization took place more markedly by using $\mathrm{Al}_{2} \mathrm{O}_{3} \mathrm{Crucible}$ than by using $\mathrm{MgO}$ or $\mathrm{C}$ crucible.

Adding $\mathrm{CaO}$ onto the melt surface was an effective method for preventing the resulfurization due to transformation of the desulfurization product of $\mathrm{MgS}$ into the more stable compound of $\mathrm{CaS}$. For prevention of the resulfurization, using the $\mathrm{CaO}-\mathrm{Al}_{2} \mathrm{O}_{3}$ mixture is less effective than using only $\mathrm{CaO}$. Since addition of the activated charcoal powders greatly decreased the transfer rate of oxygen in the atmosphere to the melt surface, it also reduced the resulfurization remarkably.
\end{abstract}

KEY WORDS: desulfurization; resulfurizaiton; magnesium vapor; pellet; magnesia; aluminothermic reduction; molten iron; ultra-low sulfur steel.

\section{Introduction}

There is an increasing interest in using magnesium as a desulfurizer for pretreatment of hot metal. This interest is based on the advantages that magnesium is a strong desulfurizer of the ability promptly to reduce the sulfur content in hot metal to an ultra-low level, and the necessary amount of slag is markedly cut down, which is not only favorable to the environment, but also reduces the temperature drop during the treatment. However, since the normal boiling point of magnesium of $1380 \mathrm{~K}$ is much lower than the temperature of hot metal pretreatment, desulfurization with magnesium has the drawbacks of low desulfurization efficiency and safety problem due to violent magnesium vaporization. Moreover, high cost of magnesium metal, and the resulfurization problem that is the reversion of sulfur from the slag to the melt after the magnesium supply terminates, also make magnesium desulfurization less attractive than the most commonly used $\mathrm{CaO}$-containing flux to be exploited as a hot metal desulfurizer.

With the purpose of overcoming these drawbacks, a great deal of research was conducted in the past thirty years. In order to make the magnesium vapor released into the hot metal in a more controlled manner, Mag-Coke, ${ }^{1,2)}$ Salt-coated magnesium, ${ }^{3)}$ Mag-lime $^{4-9)}$ and Mg-containing wire ${ }^{10)}$ methods have been developed so that the desulfurization with magnesium can be performed more safely and conveniently.

In our previous articles, ${ }^{11-14)}$ a new desulfurization method of molten iron with magnesium vapor produced in situ by carbothemic or aluminothermic reduction of magnesium oxide was reported. The cheaper magnesium oxide, instead of magnesium metal, was used as the secondary source of magnesium so that the cost of magnesium desulfurizaiton was greatly reduced. In addition, a novel method for improving desulfurization efficiency of magnesium $\left(\eta_{\mathrm{S}, \mathrm{Mg}}\right)$ by adjusting the initial magnesium molar ratio in the bubble through changing the Ar carrier gas flow rate was also proposed in our previous article. ${ }^{15)}$ By this method, a surprisingly high desulfurization efficiency of about $70 \%$ was proved to be possible for decreasing sulfur concentration from $200 \mathrm{ppm}$ to below $10 \mathrm{ppm}$, if the bubble 
size of $\mathrm{Mg}-\mathrm{Ar}$ gas was controlled to be small and the initial magnesium molar ratio in the bubble was adjusted to the optimum value.

The remaining problem for the magnesium desulfurization will be the resulfurization. This resulfurization phenomena were reported by Nakanishi et al. ${ }^{16)}$ and by Nakamura et al. ${ }^{17)}$ In our previous experiments, ${ }^{12,13)}$ the resulfurization also took place at the later stage of desulfurizaiton, when the production rate of magnesium vapor significantly decreased and the magnesium concentration in the melt dropped to a low level. However, it is pitiful that no studies have been made to elucidate the mechanism involved in the resulfurization during the magnesium desulfurization process or to develop the method for preventing the resulfurization.

The purpose of the present work is to study the mechanism that is responsible for resulfurization in the desulfurization process with magnesium vapor produced in situ by aluminothermic reduction of magnesium oxide. Effects of temperature, $\mathrm{MgO}-\mathrm{Al}$ pellet mass, oxygen partial pressure in the atmosphere, and materials of crucible on the resulfurization are investigated experimentally. The methods of prevention of resulfurization are developed.

\section{Experimental Apparatus and Procedures}

Figure 1 schematically shows the experimental apparatus. A high frequency induction furnace $(15 \mathrm{~kW}, 100 \mathrm{kHz})$ was used to melt electrolytic iron of $350 \mathrm{~g}$ in a crucible of $40 \mathrm{~mm}$ i.d. and $100 \mathrm{~mm}$ in height. The oxygen partial pressure in the atmosphere was adjusted by changing the argon and the oxygen gas flow rates blown onto the melt surface. The total gas flow rate of the argon and oxygen gases was $1.33 \times 10^{-5} \mathrm{Nm}^{3} / \mathrm{s}$. In the case of the inert atmosphere, a graphite crucible was used, while in the case of the oxidative atmosphere, an alumina or magnesia crucible was used and excess carbon was added to make the molten iron carbon-saturated. The graphite immersion tube of $11 \mathrm{~mm}$ i.d. and $15 \mathrm{~mm}$ o.d. had 5 holes of $1.0 \mathrm{~mm}$ diameter at its lower part, through which the magnesium vapor together with argon carrier gas was injected into the melt.

The pellets charged into the tube were the mixture composed of magnesia powder $(0.4 \mu \mathrm{m}$ in average diameter and purity higher than $99.99 \%$ ) and aluminum powder (75-150 $\mu \mathrm{m}$ in size and purity higher than $99.5 \%$ ). With mixing the magnesium oxide and aluminum powders at a molar ratio of $3: 2$, the pellets were formed by use of a cold isostatic press under a pressure of $150 \mathrm{MPa}$ for $1 \mathrm{~h}$. After melting the electrolytic iron, the initial sulfur concentration was adjusted by adding FeS to the molten iron, and then the tube charged with the pellets was immersed into the iron melt. The magnesium vapor produced in situ by aluminothermic reduction of magnesium oxide was injected directly into the molten iron together with the argon carrier gas, to react with sulfur dissolved in it.

In some experiments, $\mathrm{CaO}, \mathrm{CaO}+\mathrm{Al}_{2} \mathrm{O}_{3}$ or $\mathrm{C}$ powders were added onto the melt surface to study their effects on prevention of resulfurization. To clarify the role of $\mathrm{CaO}$ played in the above experiments, only $\mathrm{CaO}$ powders were added onto the melt surface without injecting $\mathrm{Mg}$ vapor in one experiment. During all the experiments, desulfurization

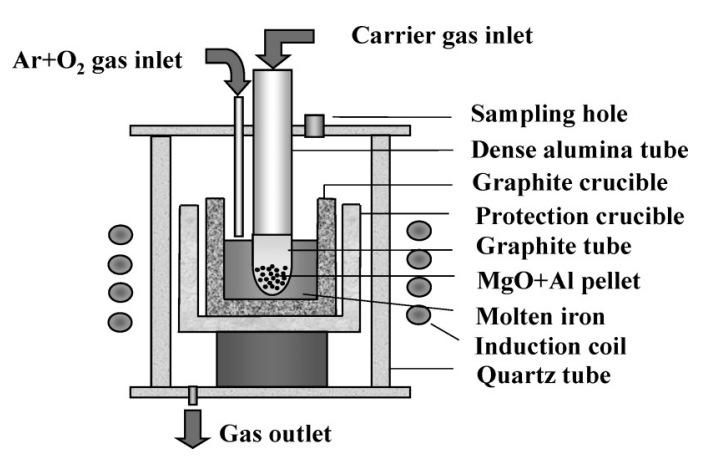

Fig. 1. Experimental apparatus.

and resulfurization processes were examined by taking samples from the melt at appropriate time intervals to analyze sulfur and magnesium contents. The sulfur content was determined by non-scattered infrared ray detector after the sample was burned in pure oxygen gas. The analyzed sulfur concentration was calibrated by two standard samples $(15 \pm 5 \mathrm{ppm}$ and $300 \pm 10 \mathrm{ppm})$. The magnesium content in the sample was determined by Induction Coupled Plasma Emission Spectroscopy (ICP) with relative scattering less than $5 \%$.

\section{Principle of Desulfurization and Resulfurization with Magnesium Vapor Produced in Situ by Alu- minothermic Reduction of Magnesium Oxide}

\subsection{Principle of Desulfurization}

The reduction of magnesium oxide by aluminum takes place in two stages. ${ }^{18)}$ At the first stage, the magnesium oxide was reduced to produce magnesium vapor and $\mathrm{MgO} \cdot \mathrm{Al}_{2} \mathrm{O}_{3}$ spinel; at the second stage, the spinel is further reduced by aluminum.

If the magnesium vapor produced by the above reductions is injected directly into the molten iron, the desulfurization proceeds:

$$
\begin{array}{r}
\operatorname{Mg}(\mathrm{g})+\underline{\mathrm{S}}=\operatorname{MgS}(\mathrm{s}) \ldots \ldots \ldots \ldots \ldots \ldots \ldots \ldots \\
\Delta G_{1}^{\circ}=-404.07+0.16921 T \quad(\mathrm{~kJ} / \mathrm{mol})^{19)} .
\end{array}
$$

Since no desulfurization slag is used in the present experiment, the activity of $\mathrm{MgS}$ is unity. And since the carbon concentration $([\% \mathrm{C}])$ is much higher than the concentrations of the other elements in melt, the Henrian activity coefficient of sulfur is given by $\log f_{\mathrm{S}}=0.11[\% \mathrm{C}] .{ }^{19)}$ The equilibrium relation between the magnesium partial pressure $\left(P_{\mathrm{Mg}}(\mathrm{atm})\right)$ in the $\mathrm{Mg}-\mathrm{Ar}$ bubble and the sulfur concentration $([\mathrm{ppmS}])$ in the melt is given by

$$
P_{\mathrm{Mg}} \cdot[\mathrm{ppmS}]=10^{4-0.11[\% \mathrm{C}]} \exp \left(\frac{-404070+169.21 T}{8.314 T}\right)
$$

Form this equation, it can be deduced that the equilibrium sulfur concentration is lower at a higher magnesium partial pressure and decreases with decreasing the operating temperature.

For discussion on the experimental results, the maximum desulfurization ratio $\left(\xi_{\mathrm{S}, \mathrm{M}}\right)$ is defined as the ratio of the dif- 
ference of sulfur concentrations between the initial value $\left([\mathrm{ppmS}]_{\mathrm{i}}\right)$ and the minimum value $\left([\mathrm{ppmS}]_{\mathrm{m}}\right)$ in the experiment, to the initial sulfur concentration.

$$
\xi_{\mathrm{S}, \mathrm{M}}=\left([\mathrm{ppmS}]_{\mathrm{i}}-[\mathrm{ppmS}]_{\mathrm{m}}\right) \times 100 /[\mathrm{ppmS}]_{\mathrm{i}}
$$

The final desulfurization ratio $\left(\xi_{\mathrm{S}, \mathrm{F}}\right)$ is introduced as

$$
\xi_{\mathrm{S}, \mathrm{F}}=\left([\mathrm{ppmS}]_{\mathrm{i}}-[\mathrm{ppmS}]_{\mathrm{f}}\right) \times 100 /[\mathrm{ppmS}]_{\mathrm{i}}
$$

where $[\mathrm{ppmS}]_{\mathrm{f}}$ is the final sulfur concentration.

The resulfurization ratio $\left(\xi_{\mathrm{S}, \mathrm{R}}\right)$ is used to give the assessment of the resulfurization degree, and can be defined as the ratio of the difference of the sulfur concentrations between the final value $\left([\mathrm{ppmS}]_{\mathrm{f}}\right)$ and the minimum value $\left([\mathrm{ppmS}]_{\mathrm{m}}\right)$, to the difference of the sulfur concentrations between the initial value $\left([\mathrm{ppmS}]_{\mathrm{i}}\right)$ and the minimum value $\left([\mathrm{ppmS}]_{\mathrm{m}}\right)$.

$$
\begin{aligned}
\xi_{\mathrm{S}, \mathrm{R}}= & \left([\mathrm{ppmS}]_{\mathrm{f}}-[\mathrm{ppmS}]_{\mathrm{m}}\right) \times 100 \\
& /\left([\mathrm{ppmS}]_{\mathrm{i}}-[\mathrm{ppmS}]_{\mathrm{m}}\right) \quad(\%)
\end{aligned}
$$

\subsection{Mechanism of Resulfurization by Decomposition of MgS}

Under the inert atmosphere, the mechanism of resulfurization is considered to be decomposition of magnesium desulfurization product of MgS.

From Speer and Parlee's results, ${ }^{20)}$ the equilibrium constant for the solution of magnesium vapor into the carbonsaturated iron is given by

$$
\begin{aligned}
& \operatorname{Mg}(\mathrm{g})=\underline{\mathrm{Mg}} \\
& \log K_{7}^{\prime}=\log \frac{[\mathrm{ppmMg}]}{10^{4} \cdot P_{\mathrm{Mg}}}=-7.82+\frac{11839}{T}
\end{aligned}
$$

By combination of Reactions (1) and (7), Eqs. (2) and (8), the formation of $\mathrm{MgS}$ by the dissolved sulfur and magnesium and the solubility product of $\mathrm{Mg}$ and $\mathrm{S}$ at various temperatures in the carbon-saturated iron can $\overline{b e}$ represented by

$$
\underline{\mathrm{Mg}}+\underline{\mathrm{S}}=\mathrm{MgS}(\mathrm{s})
$$

$[\mathrm{ppmMg}] \cdot[\mathrm{ppmS}]$

$$
=10^{0.18-0.11[\% \mathrm{C}]+11839 / T} \cdot \exp \left(\frac{-404070+169.21 T}{8.314 T}\right)
$$

The calculated relations between $[\mathrm{ppmMg}]$ and $[\mathrm{ppmS}]$ at the temperatures of $1553,1613,1673$ and $1773 \mathrm{~K}$ are plotted in Fig. 2. For comparison, the experimental results are also shown in the same figure, which will be illustrated in the later part of this paper. The calculated solubility products of [ppmMg] $[\mathrm{ppmS}]$ are 360, 570, 890 and 1740 for the saturated carbon concentrations of 4.5, 4.7, 4.8 and $5.0 \%$ at $1553,1613,1673$ and $1773 \mathrm{~K}$, respectively. From the calculated results, it is clear that the equilibrium sulfur concentration increases with decreasing the magnesium concentration when the temperature is constant. At a certain magnesium concentration, the higher equilibrium sulfur concentration at a higher temperature indicates that increasing temperature will promote resulfurization.

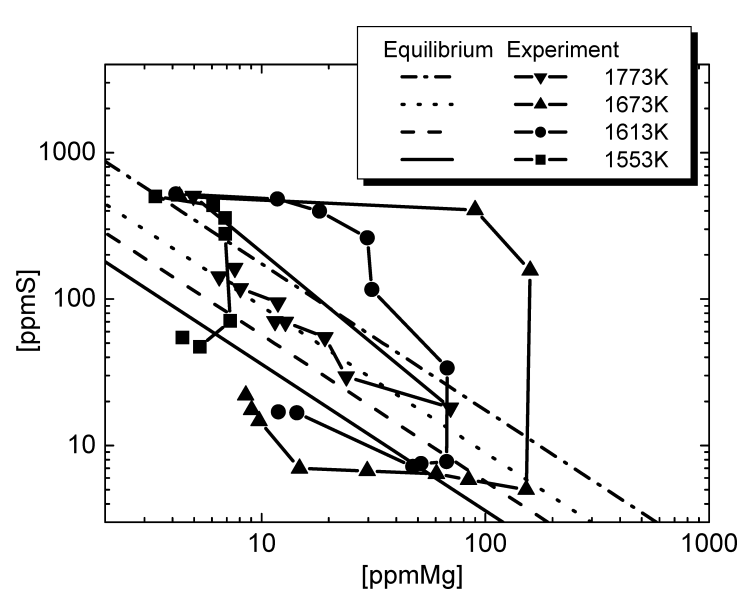

Fig. 2. Relation between $[\mathrm{ppmS}]$ and $[\mathrm{ppmMg}]$ at various temperatures.

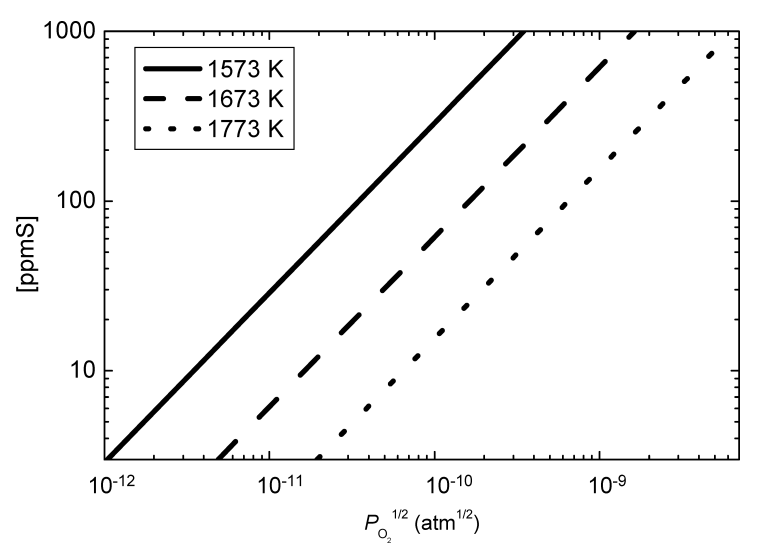

Fig. 3. Equilibrium relation between $[\mathrm{ppmS}]$ and $P_{\mathrm{O}_{2}}^{1 / 2}$.

\subsection{Mechanism of Resulfurization by Oxidation of MgS}

In order to understand the influence of the oxygen partial pressure in the atmosphere on resulfurization under the oxidative atmosphere, the mechanism of resulfurization by oxidation of $\mathrm{MgS}$ is taken into consideration. The oxidation of $\mathrm{MgS}$ can be expressed as

$$
\begin{array}{r}
\operatorname{MgS}(\mathrm{s})+1 / 2 \mathrm{O}_{2}=\operatorname{MgO}(\mathrm{s})+\underline{\mathrm{S}} \ldots \ldots \ldots \ldots . . . \\
\left.\Delta G_{11}^{\circ}=-326.48+0.03594 T \quad(\mathrm{~kJ} / \mathrm{mol})^{19}\right) .
\end{array}
$$

Since no desulfurization slag is used in the present experiment, and since $\mathrm{MgS}$ and $\mathrm{MgO}$ are in solid state, both of the activities of $\mathrm{MgS}$ and $\mathrm{MgO}$ are unity. Thus the equilibrium relation between the sulfur concentration ([ppmS]) and the oxygen partial pressure $\left(P_{\mathrm{O}_{2}}\right)$ is given by

$$
[\mathrm{ppmS}]=10^{4-0.11[\% \mathrm{C}]} \cdot P_{\mathrm{O}_{2}}^{1 / 2} \cdot \exp \left(\frac{326480-35.94 T}{8.314 T}\right)
$$

The relation of the equilibrium sulfur concentration ([ppmS]) versus root of the oxygen partial pressure in the atmosphere $\left(P_{\mathrm{O}_{2}}^{1 / 2}\right)$ is plotted in Fig. 3. It is seen that at a constant temperature, the sulfur concentration in the melt will increase with an increase in the oxygen partial pressure in the atmosphere; but when the oxygen partial pressure in 
the atmosphere is constant, it decreases with increasing temperature. One noteworthy point is that the influence of temperature on resulfurization seems to be different for the two kinds of resulfurization mechanisms. A higher temperature accelerates the resulfurization by the mechanism of decomposition of $\mathrm{MgS}$, but inhibits the resulfurization by the mechanism of oxidation of MgS. But it should be noted that to obtain the above conclusions, the magnesium concentration in the melt should be maintained constant for the decomposition of $\mathrm{MgS}$, while the oxygen partial pressure dose not change in the case of the oxidation of $\mathrm{MgS}$.

\section{Experimental Results and Discussion}

\subsection{Effect of Temperature on Resulfurization}

Figure 4 shows the changes in the sulfur and the magnesium concentrations with time at the temperatures of 1553 , 1613,1673 and $1773 \mathrm{~K}$. At the temperature of $1553 \mathrm{~K}$, the initial sulfur concentration was approximately $500 \mathrm{ppm}$, decreased to $47 \mathrm{ppm}$ in $90 \mathrm{~min}$, and then increased to $55 \mathrm{ppm}$ at $120 \mathrm{~min}$. The gradual decrease in the sulfur concentration was due to the slow aluminothermic reduction rate of magnesium oxide at $1553 \mathrm{~K}$. Even at this low temperature, the rise in sulfur concentration also appeared after $90 \mathrm{~min}$. It is seen that the magnesium concentration in the melt maintained quite a low level throughout the whole experiment of 120 min. This means that the produced magnesium vapor was used much for desulfurization of molten iron rather than dissolution into the melt.

At the higher temperatures of 1613 and $1673 \mathrm{~K}$, the desulfurization rates became faster due to the increase in the reduction rate of magnesium oxide. The sulfur concentrations decreased from about $500 \mathrm{ppm}$ to below $10 \mathrm{ppm}$ in $30 \mathrm{~min}$ and $10 \mathrm{~min}$, and then rose back to $17 \mathrm{ppm}$ and $22 \mathrm{ppm}$ at $120 \mathrm{~min}$ for the temperatures of $1613 \mathrm{~K}$ and $1673 \mathrm{~K}$, respectively. On the other hand, the magnesium concentrations rose rapidly at first, reached their peaks of $67 \mathrm{ppm}$ and $159 \mathrm{ppm}$ at $30 \mathrm{~min}$ and $10 \mathrm{~min}$ for the temperatures of $1613 \mathrm{~K}$ and $1673 \mathrm{~K}$, respectively, and then decreased slowly due to evaporation from the melt surface. From these results, it can be deduced that with increasing temperature, the increase in the aluminothermic reduction rate of magnesium oxide resulted in a faster dissolution of magnesium into the melt. However, at the later stage of the experiment, because it was close to the end of the reduction, less magnesium vapor was produced and resulfurization was liable to take place.

At a still higher temperature of $1773 \mathrm{~K}$, the sulfur concentration dropped from about 500 to $18 \mathrm{ppm}$ in only $8 \mathrm{~min}$. However, it rose gradually to $71 \mathrm{ppm}$ at $60 \mathrm{~min}$ and 119 $\mathrm{ppm}$ at $120 \mathrm{~min}$. The resulfurization occurred significantly. In this case, the magnesium concentration also rose quickly at first, reached its maximum value and then decreased slowly. The reason that the value of the maximum magnesium concentration at $1773 \mathrm{~K}$ is lower than that of $1673 \mathrm{~K}$ is not clear at present, perhaps attributing to fast vaporization of magnesium or failure to take the sample of the maximum magnesium concentration at $1773 \mathrm{~K}$.

With respect to the relationship between [ppmS] and [ppmMg] as shown in Fig. 2, it can be seen that all the experimental data are above the calculated equilibrium lines

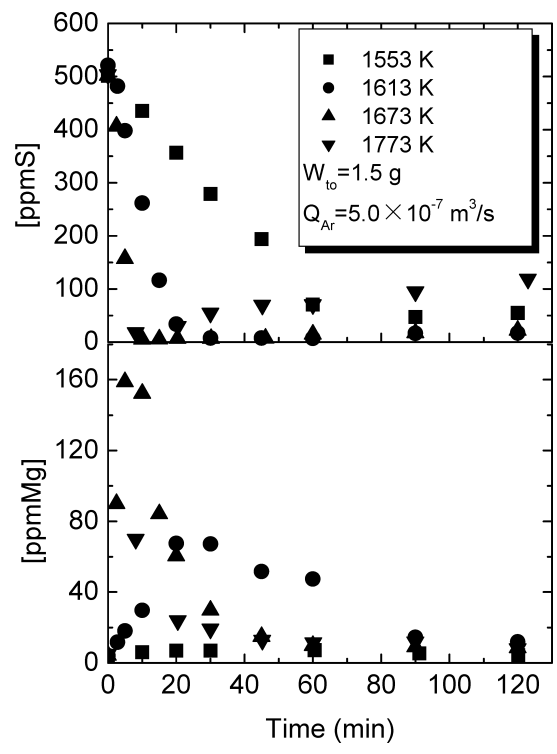

Fig. 4. Effect of temperature on changes in [ppmS] and [ppmMg] with time.

of $[\mathrm{ppmMg}] \cdot[\mathrm{ppmS}]$ at the stage of sulfur concentration decreasing. Therefore, the calculated equilibrium lines are the lowest level that the relation between [ppmMg] and [ppmS] can reach during the desulfurization period. This implies that the calculated results of $[\mathrm{ppmMg}] \cdot[\mathrm{ppmS}]$ do not conflict with the present experimental results.

On the other hand, the experimental data are below the calculated equilibrium lines after the sulfur concentrations decrease to the minimum value. In this later stage, the desulfurization ceases and the resulfurization takes place. Since the magnesium in the melt evaporates from the melt surface and transfers to the bubble surface at the later stage of desulfurization, the magnesium concentration decreases. Consequently, the sulfur concentration should rise back to keep the solubility product of $[\mathrm{ppmMg}] \cdot[\mathrm{ppmS}]$ constant. At a certain magnesium concentration, the difference of the sulfur concentrations between the equilibrium and the actual values is the driving force of this resulfurization. Because the resulfurization rate is slow due to the slow transfer rate of sulfur from $\mathrm{MgS}$ into the melt, the actual sulfur concentrations in the resulfurization period are below the calculated equilibrium lines.

At the temperatures of $1553,1613,1673$ and $1773 \mathrm{~K}$, the $\xi_{\mathrm{S}, \mathrm{F}}$ values are calculated to be $89.1,96.7,95.6$ and $76.3 \%$, and the $\xi_{\mathrm{S}, \mathrm{R}}$ values are $1.7,1.9,3.4,20.7 \%$, respectively. Because the reduction rates of magnesium oxide and vaporization rates of magnesium from the melt surface vary with temperature, the magnesium concentrations in the melt is dependent on the temperature as shown in Fig. 4. Thus it is difficult to discuss the effect of temperature on resulfurization strictly. Under the present experimental conditions, increasing temperature results in a higher resulfuriztion ratio because the solubility products of $[\mathrm{ppmMg}] \cdot[\mathrm{ppmS}]$ are increased at a higher temperature.

\subsection{Effect of Pellet Mass on Resulfurization}

For the pellet masses of $0.5,1.0$ and $1.5 \mathrm{~g}$, the changes in the sulfur and the magnesium concentrations with time are given in Fig. 5. With the initial sulfur concentration of 


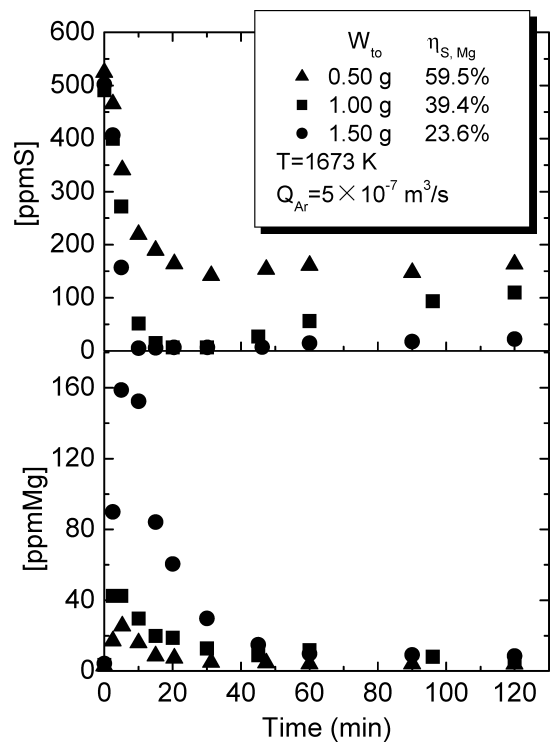

Fig. 5. Effect of pellet mass on changes in [ppmS] and [ppmMg] with time.

$500 \mathrm{ppm}$ and the mass of electrolytic iron of $350 \mathrm{~g}$, if all the magnesium oxide is reduced and the entire magnesium vapor produced is used for desulfurization, the pellets of only $0.317 \mathrm{~g}$ are theoretically required for the complete desulfurization. However, in the experiments, not all of the magnesium oxide was reduced and some of the produced magnesium vapor left the melt surface without reacting with sulfur.

In the case of the pellet mass of $0.50 \mathrm{~g}$, the sulfur concentration decreased from 524 to $142 \mathrm{ppm}$ in $30 \mathrm{~min}$, and then increased back to $163 \mathrm{ppm}$ at $120 \mathrm{~min}$. It is seen that the pellets of $0.5 \mathrm{~g}$ were not enough to decrease the sulfur concentration to below $10 \mathrm{ppm}$ and the resulfurization could occur even at such a high sulfur concentration of about $150 \mathrm{ppm}$. When the pellet mass was increased to $1.0 \mathrm{~g}$, the sulfur concentration dropped from $490 \mathrm{ppm}$ to below $10 \mathrm{ppm}$ in $20 \mathrm{~min}$. However, the resulfurization also took place markedly and the sulfur concentration rose back to $56 \mathrm{ppm}$ at $60 \mathrm{~min}$, and $110 \mathrm{ppm}$ at $120 \mathrm{~min}$. Further increasing the pellet mass to $1.5 \mathrm{~g}$ led to an even faster desulfurization rate, and thus the sulfur concentration decreased to blow $10 \mathrm{ppm}$ in only $10 \mathrm{~min}$. Moreover, the resulfurization was significantly inhibited and the sulfur concentration rose back to only $15 \mathrm{ppm}$ at $60 \mathrm{~min}$, and $22 \mathrm{ppm}$ at $120 \mathrm{~min}$. This indicates that increasing pellet mass can prevent the reversion of sulfur from slag into melt due to more magnesium vapor produced and a higher magnesium concentration remaining in the melt as shown in Fig. 5.

However, the more were the pellets added, the lower was the magnesium desulfurization efficiency. The magnesium desulfurization efficiency $\left(\eta_{\mathrm{S}, \mathrm{Mg}}\right)$, is defined as the ratio of the mass of magnesium reacting with sulfur to the mass of magnesium produced by the reduction of magnesium oxide. When the pellet mass of $0.5 \mathrm{~g}$ was used, the magnesium concentration in the melt rose quickly at first, reached the maximum value of $25 \mathrm{ppm}$ at $5 \mathrm{~min}$, and then decreased gradually to below $10 \mathrm{ppm}$ after $15 \mathrm{~min}$. Since very little magnesium dissolved into the melt and left the melt surface without reacting with sulfur, the magnesium desulfurization

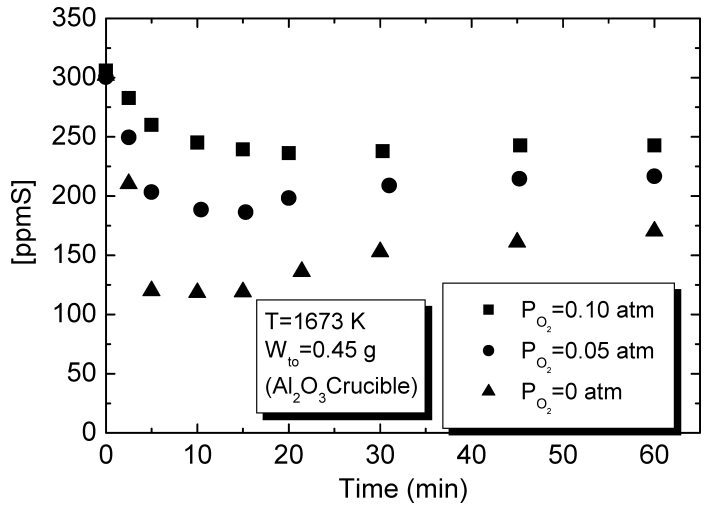

Fig. 6. Effect of oxygen partial pressure in atmosphere on desulfurization rate.

efficiency was as high as $60 \%$. In the case of the pellet mass of $1.0 \mathrm{~g}$, a similar change in the magnesium concentration with time appeared with the maximum value of $43 \mathrm{ppm}$ at $5 \mathrm{~min}$. The desulfurization efficiency markedly dropped to $39 \%$. Adding the pellet mass of $1.5 \mathrm{~g}$ resulted in more of the produced magnesium vapor dissolving into the melt, and gave the value of the magnesium concentration peak as high as $159 \mathrm{ppm}$. The magnesium desulfurization efficiency further decreased and had the value of only $24 \%$.

\subsection{Effect of Oxygen Partial Pressure in Atmosphere on Resulfurization}

The effect of the oxygen partial pressure in the atmosphere on resulfurization was studied and the experimental results are shown in Fig. 6. In the case of the oxidative atmosphere, the alumina crucible was employed and the carbon-saturated molten iron was maintained by addition of excess carbon. The less pellets were used so that the resulfurization occurred significantly and the influences of various operating parameters on the resulfurization became obvious.

Under the inert atmosphere, the sulfur concentration was reduced from about 300 to $118 \mathrm{ppm}$ in $10 \mathrm{~min}$ with the $\xi_{\mathrm{S}, \mathrm{M}}$ value of $61 \%$, and then gradually rose back to $170 \mathrm{ppm}$ at 60 min with the $\xi_{\mathrm{S}, \mathrm{F}}$ value of $43 \%$. When the oxygen partial pressure in the atmosphere was adjusted to $0.05 \mathrm{~atm}$, the sulfur concentration was lowered from about $300 \mathrm{ppm}$ to $186 \mathrm{ppm}$ in $15 \mathrm{~min}$ with the $\xi_{\mathrm{S}, \mathrm{M}}$ value of $38 \%$, and then it rose slowly to $217 \mathrm{ppm}$ and the $\xi_{\mathrm{S}, \mathrm{F}}$ value dropped to $28 \%$. Up to $0.10 \mathrm{~atm}$ was the oxygen partial pressure raised, the values of $\xi_{\mathrm{S}, \mathrm{M}}$ and $\xi_{\mathrm{S}, \mathrm{F}}$ were down to $23 \%$ and $21 \%$, respectively. From these results, one can come to the conclusion that the resulfurization is promoted with the increase in the oxygen partial pressure in the atmosphere. This is in agreement with the calculated results at a constant temperature as shown in Fig. 3. Moreover, since both of the values of $\xi_{\mathrm{S}, \mathrm{M}}$ and $\xi_{\mathrm{S}, \mathrm{F}}$ are decreased, it can be deduced that the resulfurization proceeds simultaneously with the desulfurization process.

\subsection{Comparison of Resulfurization by Use of Graphite, Magnesia and Alumina Crucible}

Graphite, magnesia and alumina crucibles were used to investigate the influence of the materials of crucible on resulfurization. With a temperature of $1673 \mathrm{~K}$, inert atmos- 


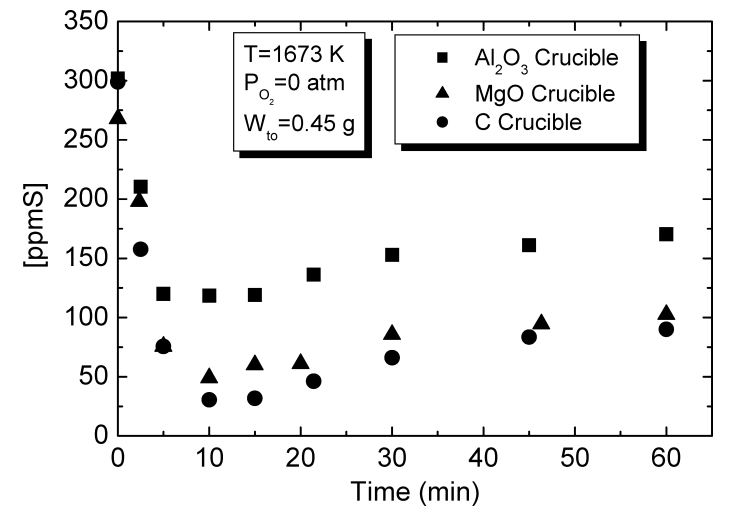

Fig. 7. Comparison of desulfurization rates among using $\mathrm{C}$, $\mathrm{MgO}$ and $\mathrm{Al}_{2} \mathrm{O}_{3}$ crucibles.

phere and pellet mass of $0.45 \mathrm{~g}$, the experimental results are presented in Fig. 7. Although using the magnesia crucible did not give appreciable changes in the desulfurization and resulfurization rates comparing with using graphite crucible, using the alumina crucible pronouncedly decreased the desulfurization rate. The values of $\xi_{\mathrm{S}, \mathrm{M}}$ and $\xi_{\mathrm{S}, \mathrm{F}}$, were $90 \%$ and $70 \%$ with the graphite crucible, but they were only $61 \%$ and $44 \%$ with the alumina crucible, respectively. These results can be explained by both of the mechanisms of resulfurization by the decomposition and by the oxidation of $\mathrm{MgS}$.

The reaction of the dissolved magnesium in the melt with the alumina crucible is described as

$$
\begin{gathered}
\mathrm{Al}_{2} \mathrm{O}_{3}+3 \underline{\mathrm{Mg}}=3 \mathrm{MgO}+2 \underline{\mathrm{Al}} \ldots \ldots \ldots . . . . \\
\Delta G_{14}^{\circ}=44.84-0.21396 \mathrm{~T} \quad(\mathrm{~kJ} / \mathrm{mol})^{19)}
\end{gathered}
$$

Equation (15) gives that $\Delta G_{14}^{\circ}=-313.12 \mathrm{~kJ} / \mathrm{mol}$ at $1673 \mathrm{~K}$. It is also possible to form spinel according to

$$
\begin{gathered}
4 \mathrm{Al}_{2} \mathrm{O}_{3}(\mathrm{~s})+3 \underline{\mathrm{Mg}}=3\left(\mathrm{MgO} \cdot \mathrm{Al}_{2} \mathrm{O}_{3}\right)(\mathrm{s})+2 \underline{\mathrm{Al}} \ldots . . \\
\Delta G_{16}^{\circ}=-17.43-0.2611 T \quad(\mathrm{~kJ} / \mathrm{mol})^{19,20,21)} \ldots \ldots .
\end{gathered}
$$

where $\Delta G_{16}^{\circ}=-454.25 \mathrm{~kJ} / \mathrm{mol}$ at $1673 \mathrm{~K}$. So, the dissolved magnesium produced by the decomposition of $\mathrm{MgS}$ is liable to be consumed by the reaction with $\mathrm{Al}_{2} \mathrm{O}_{3}$ crucible. The decomposition of $\mathrm{MgS}$ is, therefore, promoted and the resulfurization rate becomes fast in the case of $\mathrm{Al}_{2} \mathrm{O}_{3}$ crucible.

On the other hand, considering the reaction between $\mathrm{MgO}$ and $\mathrm{Al}_{2} \mathrm{O}_{3}$, and using the free energy data obtained by K. Fujii et al., ${ }^{21)}$ one can obtain:

$$
\begin{gathered}
\mathrm{Al}_{2} \mathrm{O}_{3}(\mathrm{~s})+\mathrm{MgO}(\mathrm{s})=\mathrm{MgO} \cdot \mathrm{Al}_{2} \mathrm{O}_{3}(\mathrm{~s}) \ldots \\
\Delta G_{18}^{\circ}=-20.790-0.0157 T \quad(\mathrm{~kJ} / \mathrm{mol})^{21)}
\end{gathered}
$$

By combination of Eqs. (11) and (18), in the case of $\mathrm{Al}_{2} \mathrm{O}_{3}$ crucible, the resulfurization reaction together with the associated Gibbs free energy change is given by

$$
\begin{gathered}
\operatorname{MgS}(\mathrm{s})+1 / 2 \mathrm{O}_{2}+\mathrm{Al}_{2} \mathrm{O}_{3}=\mathrm{MgO} \cdot \mathrm{Al}_{2} \mathrm{O}_{3}+\underline{\mathrm{S}} \ldots \ldots . . \\
\Delta G_{20}^{\circ}=-347.27+0.02024 T \quad(\mathrm{~kJ} / \mathrm{mol}) \ldots \ldots \ldots .
\end{gathered}
$$

where $\Delta G_{20}^{\circ}$ is $-313.41 \mathrm{~kJ} / \mathrm{mol}$, which is lower than $\Delta G_{11}^{\circ}$ of $-266.35 \mathrm{~kJ} / \mathrm{mol}$ at $1673 \mathrm{~K}$. So, in the case of $\mathrm{Al}_{2} \mathrm{O}_{3}$ cru-

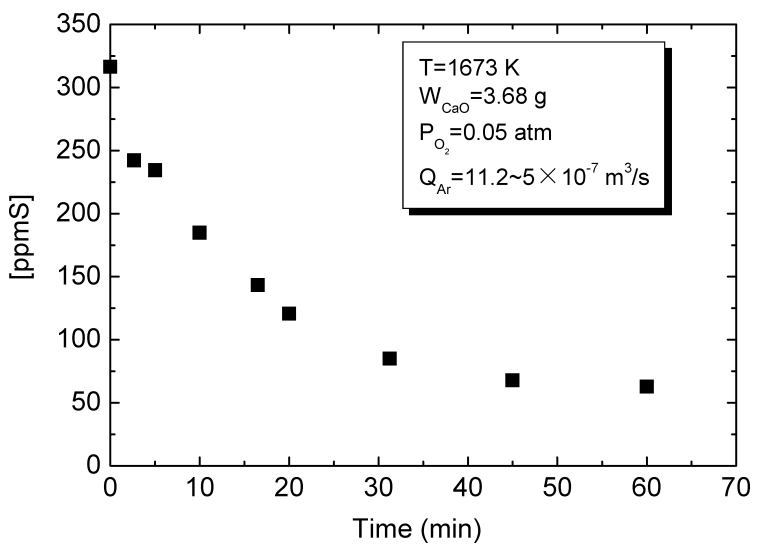

Fig. 8. Change in sulfur concentration with time by use of $\mathrm{CaO}$.

cible, the oxidation of $\mathrm{MgS}$ will be promoted and the resulfurization rate will become fast.

\subsection{Prevention of Resulfurization by Addition of $\mathrm{CaO}$}

It is a well-known fact that lime is the most commonly used desulfurizer in pretreatment of hot metal. However, it is also well recognized that lime has such a high melting point of $2850 \mathrm{~K}$ that it cannot melt down at the pretreatment temperature of hot metal. This results in the slow desulfurization rate by use of lime. To clarify the influence of lime addition on prevention of resulfurization in the desulfurization process with magnesium, a desulfurization result using only lime is presented in Fig. 8. During the experiment, argon gas was blown into the melt through a graphite immersion tube, with almost the same gas flow rate as that in the present magnesium desulfurization process with the pellet mass of $0.45 \mathrm{~g}$ and at Ar carrier gas flow rate of $5 \times 10^{-7} \mathrm{~m}^{3} / \mathrm{s}$. The argon gas flow rate in $\mathrm{CaO}$ desulfurization was decreased gradually from the initial value of $1.12 \times 10^{-6} \mathrm{~m}^{3} / \mathrm{s}$ to the value of $5 \times 10^{-7} \mathrm{~m}^{3} / \mathrm{s}$ after 20 min. In addition, the added mass of $\mathrm{CaO}$ was $3.68 \mathrm{~g}$, which corresponded to the specific reagent consumption of $10 \mathrm{~kg} /$ ton. The sulfur concentration was decreased slowly from $316 \mathrm{ppm}$ to $63 \mathrm{ppm}$ in $60 \mathrm{~min}$. No resulfurization was observed even at the later stage of desulfurization. This indicates that the product of desulfurization with lime, $\mathrm{CaS}$, is of quite a high stability. It is hard to decompose or be oxidized by the oxygen in the atmosphere.

By use of the alumina crucible, the influence of lime addition onto the melt surface on prevention of resulfurization in the magnesium desulfurization process is shown in Fig. 9. Lime of the masses of $0,0.58,1.84$ and $3.68 \mathrm{~g}$ was added onto the melt surface to study the effect of the amount of lime addition on resulfurization. Without lime added onto the melt surface, the sulfur concentration dropped from 300 to $186 \mathrm{ppm}$ in $15 \mathrm{~min}$, and then rose back to $217 \mathrm{ppm}$ at 60 min. When $0.58 \mathrm{~g}$ of lime was added onto the melt surface, the sulfur concentration was decreased to a lower level of $157 \mathrm{ppm}$ in $20 \mathrm{~min}$, and increased to $181 \mathrm{ppm}$ at $60 \mathrm{~min}$. With adding $1.84 \mathrm{~g}$ of lime, the resulfurization was completely prevented and the sulfur concentration was decreased to $126 \mathrm{ppm}$ in a sustainable way. Further increasing the amount of lime to $3.68 \mathrm{~g}$ gave an even faster desulfurization rate and the final sulfur concentration dropped down to $110 \mathrm{ppm}$ at $60 \mathrm{~min}$. 


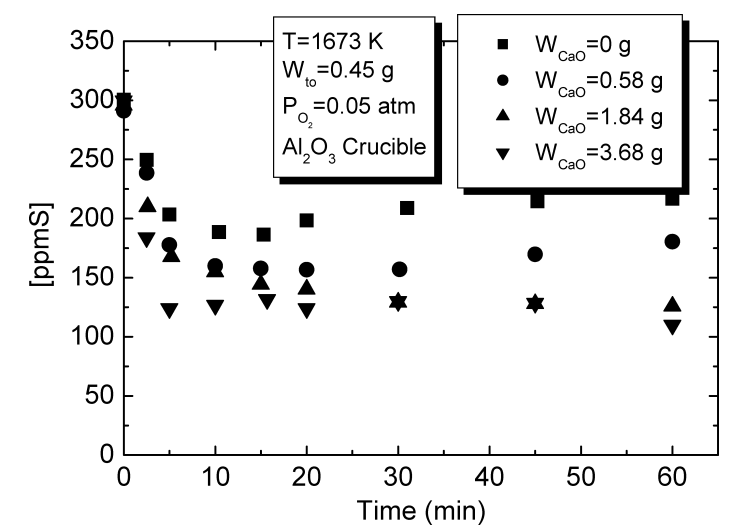

Fig. 9. Effect of lime addition on desulfurization rate using $\mathrm{Al}_{2} \mathrm{O}_{3}$ crucible.

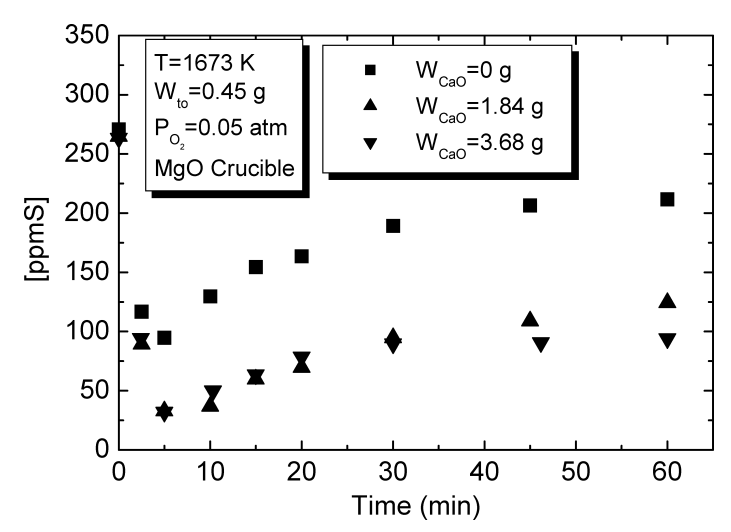

Fig. 10. Effect of lime addition on desulfurization rate using $\mathrm{MgO}$ crucible.

With respect to the influence of lime addition on resulfurization in the magnesium desulfurization process, the following reaction can be written:

$$
\begin{aligned}
& \operatorname{MgS}(\mathrm{s})+\mathrm{CaO}(\mathrm{s})=\mathrm{CaS}(\mathrm{s})+\mathrm{MgO}(\mathrm{s}) \\
& \Delta G_{22}^{\circ}=-97.82+0.0063 T \quad(\mathrm{~kJ} / \mathrm{mol})
\end{aligned}
$$

The free energy change is $-87.28 \mathrm{~kJ} / \mathrm{mol}$ at $1673 \mathrm{~K}$. This means the reaction is liable to take place under the present experimental conditions. Since complete desulfurization of molten iron of $368 \mathrm{~g}$ with the initial sulfur concentration of $300 \mathrm{ppm}$ will give the product of $\mathrm{MgS}$ of $0.19 \mathrm{~g}$, from Reaction (22), $0.58 \mathrm{~g}$ of $\mathrm{CaO}$ is about three times the amount theoretically reacting with $0.19 \mathrm{~g}$ of $\mathrm{MgS} .1 .84 \mathrm{~g}$ and $3.68 \mathrm{~g}$ of $\mathrm{CaO}$ are of the specific reagent consumptions of 5 and $10 \mathrm{~kg} / \mathrm{ton}$, respectively. In terms of the effect of prevention of resulfurization by adding lime, the very fast desulfurization rate implies that the desulfurization proceeds mainly by the combination between sulfur and magnesium, although the effect of direct desulfurization by lime can not be ruled out. Subsequently, the produced MgS reacts with $\mathrm{CaO}$ and turns into $\mathrm{CaS}$ and $\mathrm{MgO}$ to prevent resulfurization, because $\mathrm{CaS}$ has a much higher stability than $\mathrm{MgS}$.

Because the materials of crucible markedly affect the resulfurization, the influence of lime addition on resulfurization is restudied using the magnesia crucible. The results are shown in Fig. 10. Without lime added onto the melt surface, the sulfur concentration was lowered rapidly from

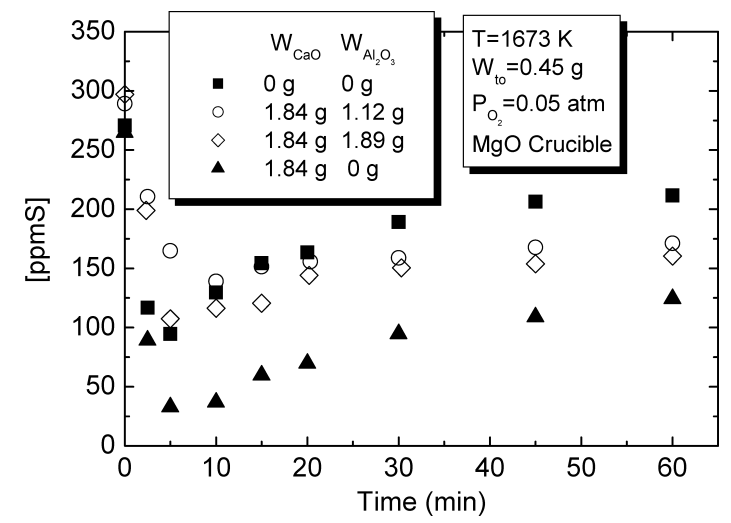

Fig. 11. Effect of addition of the lime and alumina mixture on desulfurization rate.

about 270 to $94 \mathrm{ppm}$ in only $5 \mathrm{~min}$, but rose back to $211 \mathrm{ppm}$ at $60 \mathrm{~min}$. By addition of $1.84 \mathrm{~g}$ and $3.68 \mathrm{~g}$ of lime, the sulfur concentration was deceased to 33 and $32 \mathrm{ppm}$, but also returned to 124 and $94 \mathrm{ppm}$ at $60 \mathrm{~min}$, respectively. The values of $\xi_{\mathrm{S}, \mathrm{M}}$ were $65.0,87.6$ and $87.9 \%$, and the values of $\xi_{\mathrm{S}, \mathrm{R}}$ were $46.4,39.5$ and $26.8 \%$, for adding lime of $0,1.84$ and $3.68 \mathrm{~g}$, respectively. Despite the great decrease in $\xi_{\mathrm{S}, \mathrm{R}}$ by adding more lime, it is seen that adding lime up to $3.68 \mathrm{~g}$ could not completely prevent reversion of sulfur from slag into melt in the case of using the magnesia crucible.

By comparison with the desulfurizaiton using alumina crucible, the lowest reached sulfur concentration was greatly decreased by use of magnesia crucible. This result is attributed to the same reason that is responsible for the result in Fig. 7. On the other hand, in the case of magnesia crucible, addition of lime could only partly prevent resulfurization. But in the case of alumina crucible, resulfurization was almost completely prevented. Perhaps this is because in the case of magnesia crucible, the melt was desulfurized to a lower level, and thus the resulfurization rate is faster than that using the alumina crucible. The reasons are not clear at present and should be further studied.

\subsection{Prevention of Resulfurization by Addition of $\mathrm{CaO}-\mathrm{Al}_{2} \mathrm{O}_{3}$ Mixture}

Figure 11 shows the effect of addition of $\mathrm{CaO}-\mathrm{Al}_{2} \mathrm{O}_{3}$ mixture on prevention of resulfurizaition. The magnesia crucible was employed. The mixture of $1.84 \mathrm{~g} \mathrm{CaO}$ and $1.89 \mathrm{~g} \mathrm{Al}_{2} \mathrm{O}_{3}$ has a low melting point of $1633 \mathrm{~K}$. The mixture of $1.84 \mathrm{~g} \mathrm{CaO}$ and $1.12 \mathrm{~g} \mathrm{Al}_{2} \mathrm{O}_{3}$ has a molar ratio of $\mathrm{CaO}$ and $\mathrm{Al}_{2} \mathrm{O}_{3}$ of 3 to 1 . The desulfurization results without addition of $\mathrm{CaO}$ and $\mathrm{Al}_{2} \mathrm{O}_{3}$, and with addition of only $1.84 \mathrm{~g} \mathrm{CaO}$ are also shown in the same figure to make a comparison with the present results.

When neither $\mathrm{CaO}$ nor $\mathrm{CaO}-\mathrm{Al}_{2} \mathrm{O}_{3}$ was added onto the melt surface, the sulfur concentration was reduced from 271 to $95 \mathrm{ppm}$ in $5 \mathrm{~min}$, and then went back to $212 \mathrm{ppm}$ at $60 \mathrm{~min}$. In the case of adding $\mathrm{CaO}$ of $1.84 \mathrm{~g}$ and $\mathrm{Al}_{2} \mathrm{O}_{3}$ of $1.12 \mathrm{~g}$, the sulfur concentration dropped from 289 to 139 ppm in $10 \mathrm{~min}$ and rose back to $171 \mathrm{ppm}$ at $60 \mathrm{~min}$. In the case of adding $\mathrm{CaO}$ of $1.84 \mathrm{~g}$ and $\mathrm{Al}_{2} \mathrm{O}_{3}$ of $1.89 \mathrm{~g}$, the sulfur concentration decreased from 297 to $107 \mathrm{ppm}$ in $5 \mathrm{~min}$ and returned to $160 \mathrm{ppm}$ at $60 \mathrm{~min}$. When $\mathrm{CaO}$ of $1.84 \mathrm{~g}$ was added onto the melt surface, the lowest sulfur concentration 


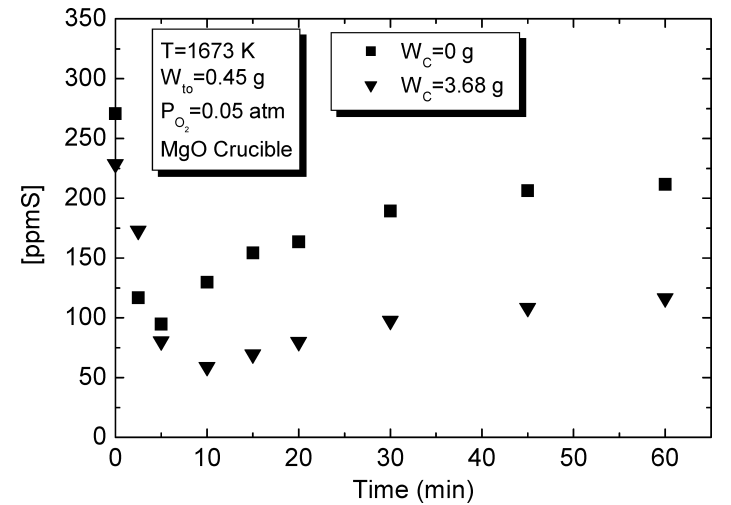

Fig. 12. Effect of addition of the activated charcoal powders on desulfurization rate.

was $33 \mathrm{ppm}$ and the final sulfur concentration was $124 \mathrm{ppm}$.

The values of $\xi_{\mathrm{S}, \mathrm{F}}$ were $22,41,46$ and $53 \%$ for no addition of $\mathrm{CaO}$ and $\mathrm{Al}_{2} \mathrm{O}_{3}$, adding $\mathrm{CaO}$ of $1.84 \mathrm{~g}$ and $\mathrm{Al}_{2} \mathrm{O}_{3}$ of $1.12 \mathrm{~g}$, adding $\mathrm{CaO}$ of $1.84 \mathrm{~g}$ and $\mathrm{Al}_{2} \mathrm{O}_{3}$ of $1.89 \mathrm{~g}$, and adding only $\mathrm{CaO}$ of $1.84 \mathrm{~g}$, respectively. For prevention of resulfurizaiton, adding the mixture of $\mathrm{CaO}$ and $\mathrm{Al}_{2} \mathrm{O}_{3}$ is less effective than adding only $\mathrm{CaO}$. This is because with $\mathrm{Al}_{2} \mathrm{O}_{3}$ on the melt surface, the dissolved magnesium produced by the decomposition of $\mathrm{MgS}$ or $\mathrm{MgO}$ produced by the oxidation of $\mathrm{MgS}$ tends to react with $\mathrm{Al}_{2} \mathrm{O}_{3}$. This will result in weakening the prevention of resulfurization.

\subsection{Prevention of Resulfurization by Addition of $\mathbf{C}$}

Since the resulfurization rate is greatly affected by the oxygen partial pressure in the atmosphere, it is possible to prevent resulfurization by inhibitng oxygen from transfering to the melt surface and reducing the oxygen partial pressure on the melt surface. Addition of activated charcoal powders onto the melt surface was tried and the result is shown in Fig. 12. For comparison, the desulfurization result without adding the activated charcoal powders is also depicted in the same figure. The magnesia crucible was used. In comparison with that the sulfur concentration decreased to just $95 \mathrm{ppm}$ in $5 \mathrm{~min}$, then rose back to a high value of $211 \mathrm{ppm}$ without addition of the activated charcoal powders, the sulfur concentration was decreased to $59 \mathrm{ppm}$, then returned to just $116 \mathrm{ppm}$ with addition of the activated charcoal powders of $3.68 \mathrm{~g}$. Addition of the activated charcoal powders had a significant advantage of prevention of the resulfurization. Since the layer of the activated charcoal powders was formed on the melt surface, the transfer of oxygen in the atmosphere to the melt surface was greatly inhibited and the oxygen partial pressure on the melt surface was reduced, and thus the driving force for the oxidation of $\mathrm{MgS}$ was decreased. As a result, the resulfurization was markedly prevented.

\section{Conclusions}

To develop a new desulfurization process with magnesium vapor produced in situ by aluminothermic reduction of magnesium oxide, the present work concentrates on elucidation of the mechanism that is responsible for resulfurization, clarification of the influences of the operating parameters on resulfurization and proposal of the methods that can prevent resulfurizaiton. The main conclusions are drawn as follows:

(1) The resulfurization in the desulfurization process with magnesium can proceed in two ways. Under the inert atmosphere, the resulfurization takes place by decomposition of $\mathrm{MgS}$, which is the product of magnesium desulfurization that floats up to the melt surface. Under the oxidative atmosphere, the resulfurization proceeds by oxidation of $\mathrm{MgS}$.

(2) Increasing the temperature accelerated the reduction of $\mathrm{MgO}$, and thus resulted in a less magnesium vapor produced at the later stage of desulfurization. Moreover, the higher temperature also brought about a higher equilibrium sulfur concentration. Therefore, a higher temperature resulted in a higher resulfurization ratio under the present experimental conditions. Using more pellets was an effective method of preventing resulfurization. But it led to a decrease in the desulfurization efficiency of magnesium. Resulfurization proceeded more remarkably under a higher oxygen partial pressure in the atmosphere.

(3) By use of the alumina crucible, the desulfurization was greatly hindered and the resulfurization was promoted. This is because the dissolved magnesium or produced magnesia could react with alumina, and the decomposition or the oxidation of $\mathrm{MgS}$ was accelerated.

(4) Because the desulfurization rate was rather low by use of only $\mathrm{CaO}$, it can be deduced that the magnesium was largely responsible for the desulfurization, and $\mathrm{CaO}$ served mainly as a reagent to transform the desulfurization product of $\mathrm{MgS}$ into the stable compound of $\mathrm{CaS}$, so that the resulfurization was prevented. As a result, in the desulfurization process with magnesium, addition of $\mathrm{CaO}$ onto the melt surface significantly prevented the resulfurization. However, the prevention of resulfurization could not be improved by using the $\mathrm{CaO}$ and $\mathrm{Al}_{2} \mathrm{O}_{3}$ mixture.

(5) It has been proved that adding activated charcoal powders onto the melt surface could effectively prevent resulfurization due to the decrease in the transfer rate of oxygen in the atmosphere to the melt surface.

\section{Acknowledgement}

This study was supported in part by Grant-in-Aid for Scientific Research (16360372) from the Ministry of Education, Science, Sports and Culture of Japan.

\section{REFERENCES}

1) S. Yamaguchi, T. Uemura, H. Nashiwa and H. Sugita: Ironmaking Steelmaking, 5 (1977), 276.

2) W. H. Duquette, N. R. Griffing and T. W. Miller: Open Hearth Proceedings, 56 (1973), 79.

3) W. G. Wilson and A. Mclean: Desulfurization of Iron and Steel and Sulfide Shape Control, ISS-AIME, Warrendale, PA, (1980), 77.

4) P. J. Koros, R. G. Petrushka and R. G. Kerin: Iron Steelmaker, 4 (1977), 34.

5) A. Aoyagi, Z. Mukuda, S. Takada and S. Oomiya: CAMP-ISIJ, 7 (1994), 221.

6) T. Fujita, K. Matuo, S. Nakashima, K. Semura and M. Entou: CAMP-ISIJ, 7 (1994), 218.

7) K. Kimura, I. Kikuchi, S. Kohei, Y. Komatsu, Z. Hukumi and T. Toyota: CAMP-ISIJ, 8 (1995), 105.

8) J. Hirama, K. Gennai, Y. Hiraga and Y. Nakashima: CAMP-ISIJ, 8 (1995), 104.

9) K. Yonezawa S. Sasakawa and S. Kitamura: CAMP-ISIJ, 6 (1993), 1070. 
ISIJ International, Vol. 45 (2005), No. 12

10) Y. Hiraga, K. Gennai, Y. Nakashima and J. Hirama: CAMP-ISIJ, 9 (1996), 225.

11) J. Yang, S. Ozaki, R. Kakimoto, K. Okumura, M. Kuwabara and M. Sano: ISIJ Int., 41 (2001), 945.

12) J. Yang, K. Okumura, M. Kuwabara and M. Sano: ISIJ Int., 41 (2001), 965.

13) J. Yang, K. Okumura, M. Kuwabara and M. Sano: ISIJ Int., 42 (2002), 595.

14) J. Yang, K. Okumura, M. Kuwabara and M. Sano: ISIJ Int., 42 (2002), 685.

15) J. Yang, K. Okumura, M. Kuwabara and M. Sano: Metall. Trans. B,
34B (2003), 619

16) K. Nakanishi, A. Ejima, T. Suzuki and F. Sudo: Tetsu-to-Hagané, 64 (1978), 1323.

17) Y. Nakamura and N. Tokumitsu: Tetsu-to-Hagané, 60 (1974), S438.

18) L. Hong, K. Okumura and M. Sano: Metall. Trans. B, 30B (1999), 1003.

19) Handbook of Iron and Steel, ed. by ISIJ, Maruzen, Tokyo, (1981), 14.

20) M. C. Speer and N. A. D. Parlee: Cast Met. Res. J., 8 (1972), 122.

21) K. Fujii, T. Nagasaka and M. Hino: ISIJ Int., 40 (2000), 1059. 